\title{
Splitting failure in side walls of a large-scale underground cavern group: a numerical modelling and a field study
}

\author{
Zhishen Wang ${ }^{1}$, Yong $\mathrm{Li}^{1,2^{*}}$, Weishen Zhu' ${ }^{1}$ Yiguo Xue ${ }^{1}$ and Song $\mathrm{Yu}^{2}$
}

*Correspondence: yongli@
sdu.edu.cn
${ }^{1}$ Geotechnical and Structural
Engineering Research
Center, Shandong University,
Jinan 250061, Shandong
Province, People's Republic
of China
Full list of author information
is available at the end of the
article

article

\begin{abstract}
Vertical splitting cracks often appear in side walls of large-scale underground caverns during excavations owing to the brittle characteristics of surrounding rock mass, especially under the conditions of high in situ stress and great overburden depth. This phenomenon greatly affects the integral safety and stability of the underground caverns. In this paper, a transverse isotropic constitutive model and a splitting failure criterion are simultaneously proposed and secondly programmed in FLAC3D to numerically simulate the integral stability of the underground caverns during excavations in Dagangshan hydropower station in Sichuan province, China. Meanwhile, an in situ monitoring study on the displacement of the key points of the underground caverns has also been carried out, and the monitoring results are compared with the numerical results. From the comparative analysis, it can be concluded that the depths of splitting relaxation area obtained by numerical simulation are almost consistent with the actual in situ monitoring values, as well as the trend of the displacement curves, which shows that the transverse isotropic constitutive model combining with the splitting failure criterion is appropriate for investigating the splitting failure in side walls of large-scale underground caverns and it will be a helpful guidance of predicting the depths of splitting relaxation area in surrounding rock mass.
\end{abstract}

Keywords: Transverse isotropic constitutive model, Splitting failure, High in situ stress, Large-scale underground caverns, Numerical simulation, Field monitoring

\section{Background}

In recent years, the developments of large-scale underground caverns in hydropower stations are dramatically increasing in China. A large number of underground engineering projects are being carried out, some of which are buried deep, in particular (Liu 2009; Zhu et al. 2011; Li et al. 2014). In the complex geological conditions, longitudinal splitting cracks, appearing very often in the side wall of the caverns during excavations, which can weaken the mechanical properties of the sidewall. Hibino and Motojma (1995) conducted research analyzing statistical data from a large number of monitoring supervise of 16 hydropower caverns by borehole TV and extensometer. The results showed that inside the rock wall of cavern there were opening deformation-crack propagation, joint opening, new crack generation in rock mass after excavation ( $\mathrm{Li}$ et al. 2011). In the recent decade, the stability of some underground hydropower projects is 
greatly affected by this kind of splitting failures in the surrounding rock masses of underground cavern groups (Jiang 2007; Zhu et al. 2012; Xiang et al. 2011).

The splitting failure in the sidewall may destabilize the underground engineering projects (Liu 2009), as well as reducing crane beam stability (Zhang et al. 2012) and bearing capacity (Xiang et al. 2011). Moreover, other engineering hazards such as corrosion, rock bolt cables failure and cavern leakage may be induced by the splitting failure (Wei et al. 2010).

Previous studies, such as model of crack propagation or micro crack (Dias-da-Costa et al. 2011; Yerramalli and Waas 2001; Nie et al. 2015; Haeri et al. 2014) were no longer applicable when the micro-cracks in the rock masses propagated (Haeri et al. 2015) and became large parallel splitting crack groups. Therefore, it is necessary to find a more suitable constitutive model which can determine the effectiveness of the research results.

In this paper, the location, depth and the development characteristics of the splitting failures during excavations have been numerically simulated based on a transverse isotropic constitutive model combined with a splitting failure criterion at the Dagangshan hydropower station. Also an in situ monitoring study on the displacement of key points in the underground caverns was performed. The comparative analysis between numerical simulation and in situ monitoring show that the transverse isotropic constitutive model combining with the splitting failure criterion is appropriate for investigating the splitting failure in side walls of large-scale underground caverns and it will be a helpful guidance of predicting the depths of splitting relaxation area in surrounding rock mass.

\section{A transverse isotropic constitutive model}

As shown in Fig. 1a, the splitting failure of underground caverns can be described as the stress of the side wall concentrated after the cavern excavations, which is caused by the similar compressed state near the excavation zone, resulting from the unloading on the other side of the cavern. Then the crack will extend with the continuous loading, depicted in Fig. 1b. When the stress state of the crack meets the cracking conditions, the crack will extend steadily along in the direction of the principal compressive stress.

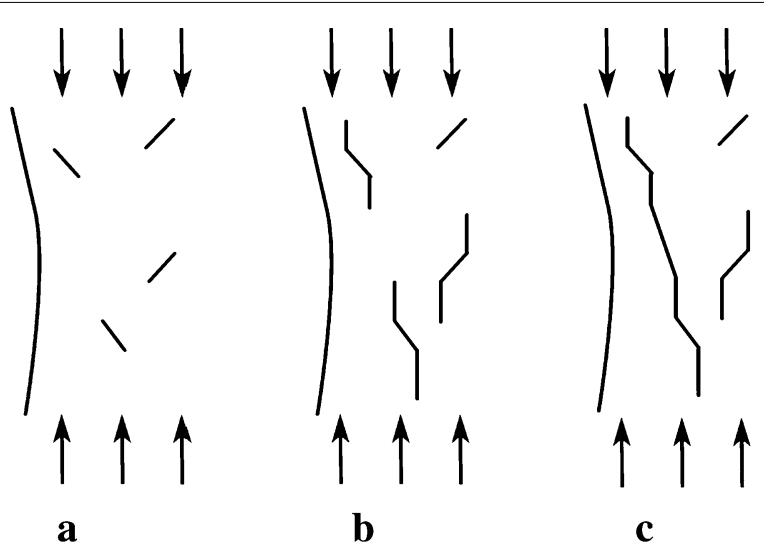

Fig. 1 Schematic diagrams of splitting failure mode of surrounding rock: a The initial condition of the surrounding rock mass after the cavern excavation; $\mathbf{b}$ the extending of the crack under the continuous loading; c large-scale splitting failure formed 
As the load continues to increase, with the effect of free boundary conditions and the interactions among the cracks, the crack propagation will not be stable. At this stage, the cracks growth will break out and large-scale splitting cracks will be formed as shown in the Fig. 1c.

Since the brittle characteristics of rock mass, the vertical splitting cracks of the rock masses between the caverns often appear during excavations. Therefore, the rock masses in splitting areas could be simplified to laminated model where the joint plane is perpendicular to the horizontal plane. This could be described by the transverse isotropic constitutive models (Jia et al. 2008).

Transverse isotropic elastomer is composed of a series of elastic symmetry planes (Ngueyep Mambou et al. 2015; Janna et al. 2012). The physico-mechanical properties of the transverse isotropic elastomer are totally different parallel to and perpendicular to the planes of elastic symmetry. The joint plane is shown as the plane of elastic symmetry (David 2012), the material parallel to the joint plane has the same physico-mechanical properties (Aboye and Nadarajah 2012), and vertical direction has different physicomechanical properties, as shown in Fig. 2. It is assumed that the XOY plane is an elastic plane and the elastic parameters of the transverse isotropic elastomer should meet the following conditions:

$$
\begin{aligned}
E_{x} & =E_{y}=E, \quad E_{z}=E^{\prime} \\
v_{x y} & =v_{y x}=v, \quad v_{z x}=v_{z y}=v^{\prime} \\
G_{x y} & =\frac{E}{2(1+v)}, \quad G_{y z}=G_{x z}=G^{\prime}
\end{aligned}
$$

The constitutive relation of the transversely isotropic elastomer can be simplified as:

$$
\left\{\begin{array}{c}
\varepsilon_{x} \\
\varepsilon_{y} \\
\varepsilon_{z} \\
\gamma_{x y} \\
\gamma_{y z} \\
\gamma_{x z}
\end{array}\right\}=[A]\left\{\begin{array}{c}
\sigma_{x} \\
\sigma_{y} \\
\sigma_{z} \\
\tau_{x y} \\
\tau_{y z} \\
\tau_{x z}
\end{array}\right\}=\left\{\begin{array}{cccccc}
a_{11} & a_{12} & a_{13} & 0 & 0 & 0 \\
& a_{11} & a_{23} & 0 & 0 & 0 \\
& & a_{33} & 0 & 0 & 0 \\
& & & a_{44} & 0 & 0 \\
& & & & a_{55} & 0 \\
& & & & & a_{55}
\end{array}\right\}\left\{\begin{array}{c}
\sigma_{x} \\
\sigma_{y} \\
\sigma_{z} \\
\tau_{x y} \\
\tau_{y z} \\
\tau_{x z}
\end{array}\right\}
$$

where $[A]$ is the flexibility matrix.

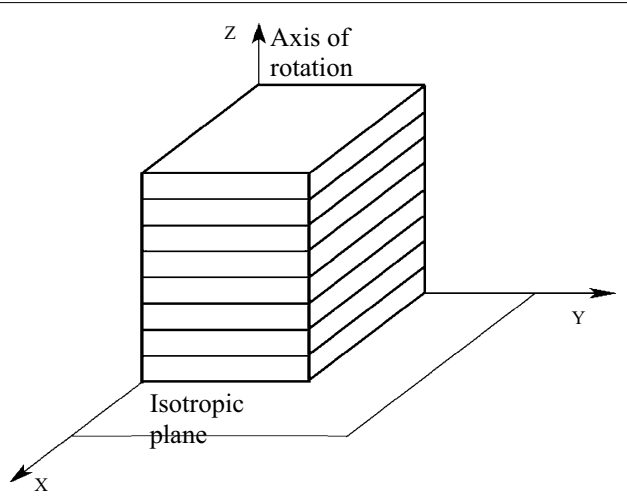

Fig. 2 Transverse isotropic material 
The parameters of flexibility matrix in Eq. (2) could be expressed as elastic constants:

$$
\begin{gathered}
a_{11}=\frac{1}{E}, \quad a_{12}=-\frac{v}{E}, \quad a_{13}=-\frac{v^{\prime}}{E} \\
a_{33}=\frac{1}{E^{\prime}}, \quad a_{44}=\frac{2(1+v)}{E}, \quad a_{55}=\frac{1}{G^{\prime}}
\end{gathered}
$$

where $E_{1}, \mu_{1}$ are the elastic modulus and Poisson's ratio of the transverse isotropic plane (XOY plane); $E_{2}, \mu_{2}$ are the elastic modulus and Poisson's ratio of the vertical transverse isotropic plane ( $\mathrm{Z}$ axis); $G_{2}$ is the shear modulus of the vertical transverse isotropic plane (perpendicular to the XOY plane).

The various parameters in the stiffness matrix [C] can be expressed as elastic constants since the stiffness matrix and compliance matrix are mutually inverse, which is $[\mathrm{C}]=[\mathrm{A}]^{-1}$.

$$
\begin{aligned}
& c_{11}=\lambda n\left(1-n \mu_{2}^{2}\right), c_{12}=\lambda n\left(\mu_{1}+n \mu_{2}^{2}\right), c_{13}=\lambda n \mu_{2}\left(1+\mu_{1}\right) \\
& c_{33}=\lambda\left(1-\mu_{1}^{2}\right), c_{44}=G_{2}, c_{66}=E /\left[2\left(1+\mu_{1}\right)\right]
\end{aligned}
$$

where $n=\frac{E_{1}}{E_{2}}, \lambda=E_{2} /\left(1+\mu_{1}\right)\left(1-\mu_{1}-2 n \mu_{2}^{2}\right)$

The nine independent elastic parameters have been reduced to five with the degeneration of the orthotropic to transverse isotropic elastomer. These are $E_{1}, E_{2}, G_{2}, \mu_{1}, \mu_{2} . G_{1}$ is not the independent elastic parameter, for $G_{1}=E_{1} /\left[2\left(1+\mu_{1}\right)\right]$. Obviously, $G_{1}$ is the function of $E_{1}$ and $\mu_{1}$.

\section{A field monitoring in Dagangshan hydropower station}

Dagangshan hydropower station, with a controlled area of $62,727 \mathrm{~km}^{2}, 81 \%$ of catchment area of Dadu River, is one of the large-scale hydropower projects in the Dadu River developed recently. The location of the hydroelectric station is at the middle reach of the Dadu River in Sichuan Province and the hydropower station is approximately $40 \mathrm{~km}$ from the Shimian City and approximately $72 \mathrm{~km}$ away from Luding City.

This hydroelectric station has 4 generator units, and the capacity of each unit is $550 \mathrm{MW}$, with a total capacity of 2, $600 \mathrm{MW}$. The capacity is 114.5 billion $\mathrm{kW} \mathrm{h}$.

The water diversion and power generation system of the hydroelectric station, which includes the main power houses, transformer chamber and tailrace surge chamber, are on the left bank of the river. The three large chambers are arranged in parallel, with axis direction is $\mathrm{NE} 55^{\circ}$, vertical buried depths are $390-520 \mathrm{~m}$ and horizontal buried depths are $310-530 \mathrm{~m}$. The total length of the main power house is $226.58 \mathrm{~m}$, the length of the crane girder is $30.80 \mathrm{~m}$, and the maximum excavation height of the main engine is $73.78 \mathrm{~m}$. The transformer chamber is $144 \mathrm{~m}$ long, $18.8 \mathrm{~m}$ wide and $25.6 \mathrm{~m}$ high. And the length, width and height of the tailrace surge chamber is $132 \mathrm{~m}, 24 \mathrm{~m}$ and $75.08 \mathrm{~m}$, respectively.

The type of the rock surrounding the underground powerhouse is mainly fine grained biotite adamellite ( $\gamma 24-1)$, and the surrounding rock partial interspersed with diabase. The rock masses of the plant area are massive and similar-massive structure. There are some weak structural planes such as faults $\mathrm{f} 57, \mathrm{f58}, \mathrm{f} 59, \mathrm{f} 60$ and etc. through the plant caverns. 
Generally, there are four groups of fracture developed in the rock masses of the plant area at the hydropower station, the length of which are 3-5 m mainly, and some are longer than $10 \mathrm{~m}$ individually. There are also some alterations on the surface of the fracture in groups. The steep angle fractures whose direction is nearly $\mathrm{SN}$ are most developed. The angle between axis of underground powerhouse, which first proposed for $\mathrm{NE} 55^{\circ}$, and the maximum principal stress is small. According to the classification of surrounding rock, the classification of surrounding rock of main power house, transformer chamber and tailrace surge chamber is between Type II and Type III. Overall, the surrounding rocks of the plant area are stable. The results of field monitoring and the reverse calculation show that the in situ stress field in the underground powerhouse area is a superposed stress field which is comprised of tectonic stress and gravity stress. The distribution of in situ stress is affected comprehensively by tectonic stress, geological structure and topography (Zhang et al. 2011). The area can be regarded as a high in situ stress area (Zhang et al. 2009) and the maximum principal stress is up to $26.9 \mathrm{MPa}$ ( $\mathrm{Li}$ 2009).

Four pre-set horizontal monitoring holes, each to a depth of $46.5 \mathrm{~m}$ and diameter of $110 \mathrm{~mm}$, have been constructed to obtain the complete values of the displacement and splitting zone of the downstream surrounding rock masses in the main power house during excavations. The layout of the holes is shown in Figs. 3 and 4. Among of them, the holes A3 and A4 that are $4.5 \mathrm{~m}$ apart and located in the rock masses between bus gallery \#3 and \#4 are put into a group for sliding extensometer and deformation resistivity instrument monitoring. Since the transformer chamber has been completely constructed, the drilling direction is from the upstream sidewall of transformer chamber to the main power house in order to make less interference suffered during excavations in the main power house.

Three types of monitoring methods were used in the field monitoring including the high-accuracy sliding extensometers, WDA-1 and borehole TV.

High-accuracy sliding extensometers made in Switzerland was used to measure the displacement changes of the surrounding rock mass.

WDA-1, a kind of high density resistivity meter, has been applied in the field resistivity monitoring. The length of the probe of WDA-1 is $150 \mathrm{~cm}$, with two electrodes of A and

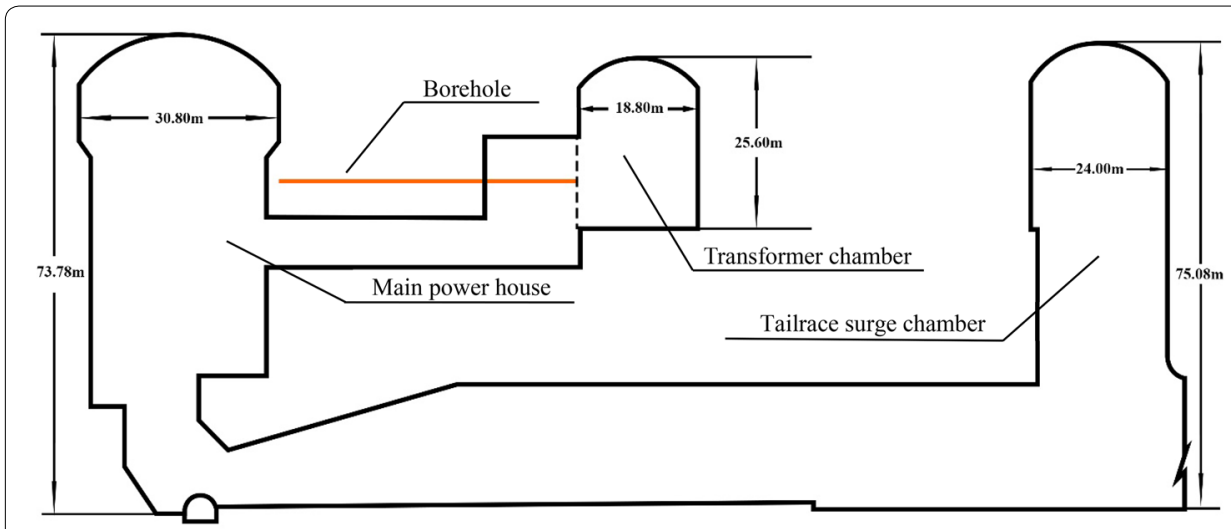

Fig. 3 The profile of the monitoring holes 


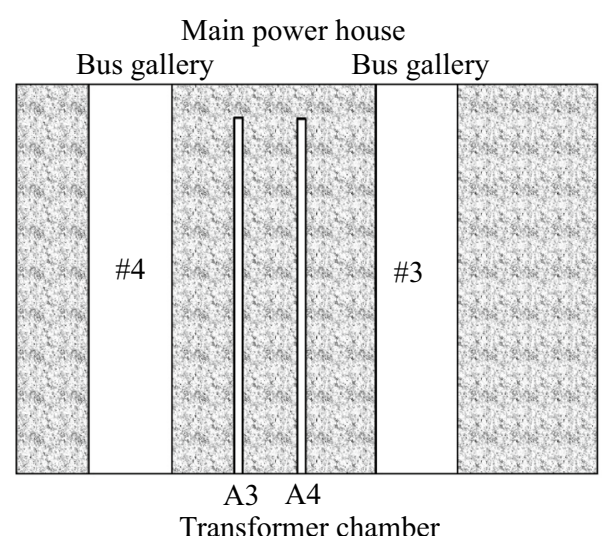

Fig. 4 The planar graph of the monitoring hole: $A 3, A 4$ are the boreholes that drilling from transformer chamber to main power house

M. Another pair of electrodes, N and B, are arranged at infinity. A and B generate current, while $\mathrm{N}$ and $\mathrm{M}$ monitor the generated voltage to obtain the resistivity changes of rock masses after calculation.

Using borehole TV, the camera probe is pushed into the horizontal monitoring holes to record video using spindles, by which the cracks number can be counted and recorded.

From the monitoring results of the three methods, the failure zones of the surrounding rock masses caused by excavation disturbance were determined. The depths of the splitting zones of the main power house are larger than those of the transformer chamber, since the larger size of the main power house. For the generator unit \#4, the depth of the splitting failure zone of the main power house is significantly larger than that of the transformer chamber.

Due to differences in accuracy and the abilities of the anti-interference of various monitoring instruments, the results of the three kinds of monitoring methods are slightly different, but the overall trend is consistent. The results monitored by the sliding extensometers could be considered more reliable than the others for its high precision, strong anti-interference and fewer interferential factors, while the remaining two could be employed as useful supplements. According to the monitoring results and combined with the engineering experience, the depth of the splitting failure zone of the \#4 generator unit is shown in Table 1.

The max displacement of the downstream sidewall of main power house is approximately $17-18 \mathrm{~mm}$ and that of upstream sidewall of transformer chamber is approximately $5 \mathrm{~mm}$.

Table 1 Depth of the splitting area of the generator unit \#4 by field monitoring

\begin{tabular}{lll}
\hline Unit section & Generator unit \#4 & \\
\hline Location & Downstream of the main power house & Upstream of the transformer chamber \\
Depth of splitting area $(\mathrm{m})$ & $13-15$ & $5-6$ \\
\hline
\end{tabular}




\section{Establishment of computational model combining with a splitting failure criterion}

\section{Stress state conditions and a prediction formula of the splitting surrounding rock}

$\mathrm{Li}$ (2007) deduced the splitting failure criterion for a fractured surrounding rock mass using a slip crack model as below:

$$
\sigma_{1} \geq \frac{K_{I C} \sqrt{\pi L}}{L\left(\sin \theta \cos ^{2} \theta-\mu \sin ^{2} \theta \cos \theta\right)}+\sigma_{3} \frac{\pi+\left(\sin \theta \cos ^{2} \theta+\mu \cos ^{3} \theta\right)}{\sin \theta \cos ^{2} \theta-\mu \cos \theta \sin ^{2} \theta}
$$

where $\mu$ is the friction coefficient of initial crack, $L$ is the average length of the initial crack $(\mathrm{m}), \theta$ is the angle between initial crack and the horizontal direction $\left(^{\circ}\right), K_{I C}$ is the fracture toughness of the rock $\left(\mathrm{MPa} \mathrm{m}{ }^{1 / 2}\right)$.

This criterion can be used to predict the depth of the splitting zone in the surrounding rock masses of underground caverns.

\section{Computational model and parameters}

In this paper, a numerical model of the main power house, transformer chamber and tailrace surge chamber of generator unit \#4 is established to calculate and analyze the stability of surrounding rock masses, illustrated in Fig. 5. The excavation process of the main power house is divided into eight steps from top to bottom, and the transformer chamber is divided into three steps and tailrace surge chamber is divided into seven steps.

The scope of the numerical model is as follows: upstream boundary: extending $300 \mathrm{~m}$ from the upstream sidewall of the main power house to upper reaches; downstream boundary: extending $300 \mathrm{~m}$ from the downstream sidewall of the tailrace surge chamber to lower reaches; top boundary: to ground elevation; bottom boundary: to $1120 \mathrm{~m}$ elevation (the elevation of the floor of the tailrace surge chamber is $920.02 \mathrm{~m}$ ). There are a number of faults and fractured areas in the domain of the numerical model. So as to facilitate the calculation, only the faults and fracture areas which has a great influence on the three major chambers is simulated in the numerical simulation.

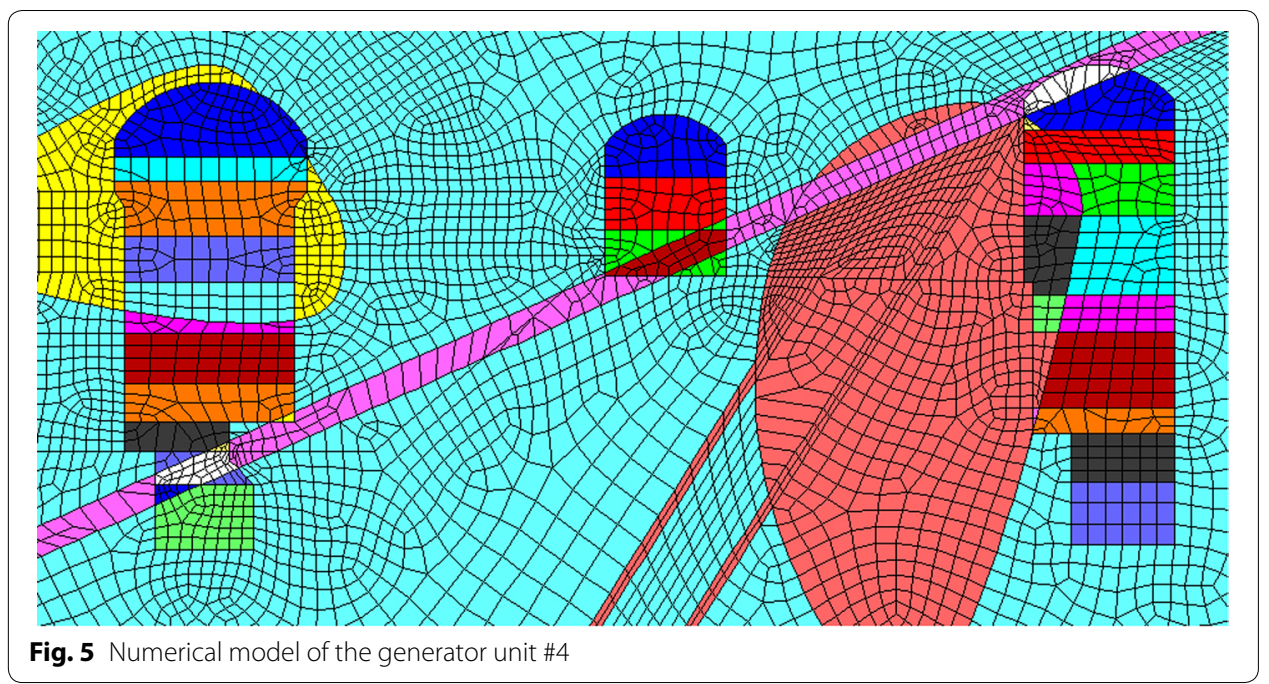


According to the results of field monitoring and inversion analysis, the physicomechanical parameters of the numerical model of the generator unit \#4 are shown in Table 2.

\section{Calculation process}

During numerical simulations, the first stage uses the Mohr-Coulomb model with the corresponding parameters in FLAC3D, and then proceeds to the excavation styles. After each step of excavation, the splitting fracture zone is determined by the criterion given in Eq. (5). Then, the structural model of the fracture zone is be transformed into the transverse isotropic model. The vertical direction parameters remain as the original while the horizontal ones are decreased. The main power house is divided into eight steps to be excavated. Therefore the numerical simulation was ceased after the eighth step excavation was completed.

The numerical simulation is carried out according to the following procedure:

1. The main parameters of Eq. (5) are determined according to the field rock mass condition;

2. Importing the numerical model into the FLAC3D;

3. Writing the Eq. (5) with the parameters into FLAC3D to gauge the stress field of the numerical model, and the parts that meet the criterion are considered that the rock mass in these positions has a splitting failure. These sections of the constitutive model are changed into transverse isotropic constitutive model.

4. Calculating the stability of the caverns during excavations.

The flow chart is shown in Fig. 6.

\section{Analysis of calculation results}

\section{General analysis of the splitting failure of surrounding rock mass}

According to the exception in field and some experiences as well as inversion analysis, the main parameters of the Eq. (5) are adopted as follows:

$$
\mu=0.2, \quad \theta=40^{\circ}, \quad \mathrm{K}_{\mathrm{IC}}=0.84 \mathrm{MPa} \mathrm{m}^{1 / 2}, \quad \mathrm{~L}=5 \mathrm{~m}
$$

Firstly, taking the parameters into the Eq. (5) and principal stress of the surrounding rock masses has been achieved, then calculating by FLAC3D. After that, the splitting area of the generator unit \#4 after eight-step excavation could be gotten and shown in Fig. 7.

Table 2 Mechanical parameters of the numerical model of the generator unit \#4

\begin{tabular}{|c|c|c|c|c|c|c|}
\hline $\begin{array}{l}\text { Rock mass } \\
\text { classification }\end{array}$ & $\begin{array}{l}\text { Bulk density } \\
\left(\mathrm{kN} / \mathrm{m}^{3}\right)\end{array}$ & $\begin{array}{l}\text { Deformation } \\
\text { modulus } \\
(\mathrm{GPa})\end{array}$ & $\begin{array}{l}\text { Friction } \\
\text { angle }\left({ }^{\circ}\right)\end{array}$ & $\begin{array}{l}\text { Cohesion } \\
\text { (MPa) }\end{array}$ & $\begin{array}{l}\text { Poisson's } \\
\text { ratio }\end{array}$ & $\begin{array}{l}\text { Tensile } \\
\text { strength } \\
(\mathrm{MPa})\end{array}$ \\
\hline$\|$ & 26.5 & 23.5 & 52.4 & 2.0 & 0.25 & 8.0 \\
\hline III & 26.5 & 9.5 & 47.7 & 1.4 & 0.27 & 6.0 \\
\hline IV & 26.5 & 2.5 & 38.7 & 0.7 & 0.35 & 4.0 \\
\hline$\|/\| \|$ & 26.5 & 16.5 & 50.2 & 1.7 & 0.26 & 7.0 \\
\hline
\end{tabular}




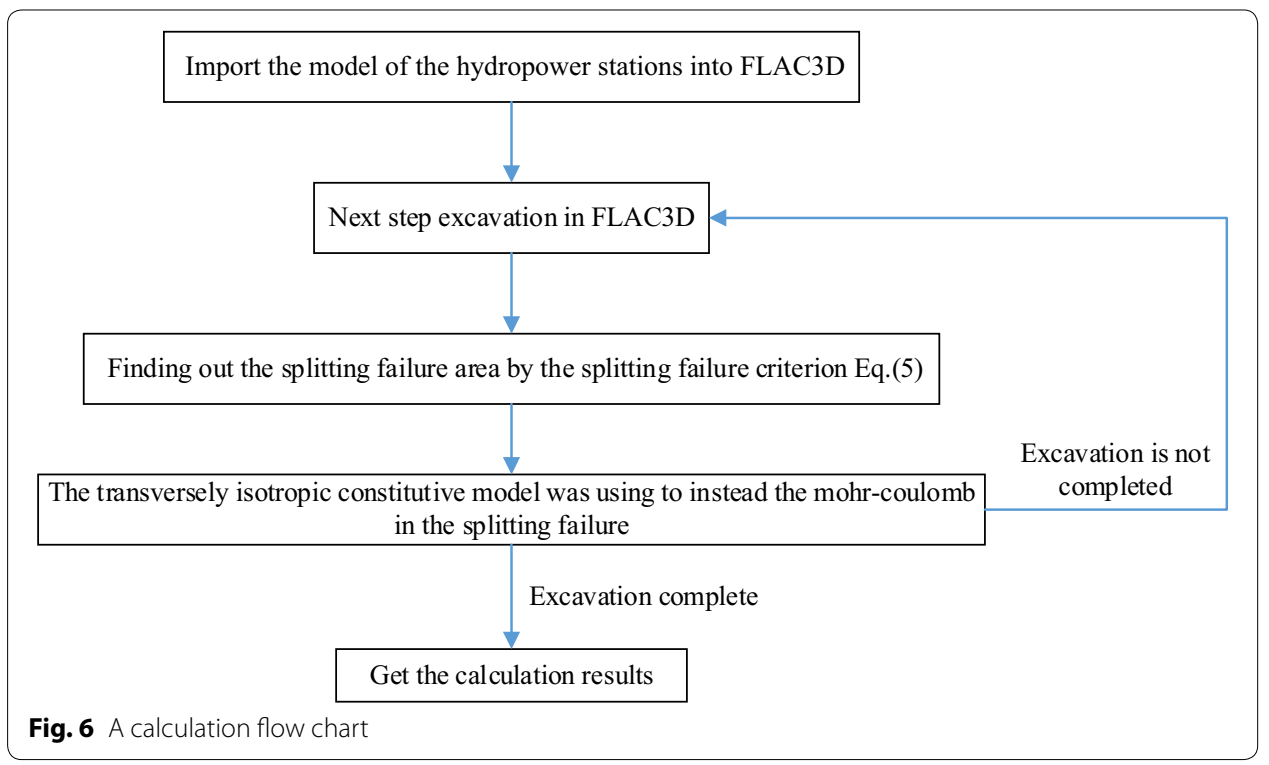

According to Fig. 7, the depth of the splitting zone of the underground caverns has been gradually increased with the excavation steps. The depth of splitting zone of the downstream sidewall of the main power house is slightly larger than that of the upstream sidewall of the main power house and that of the upstream sidewall of the transformer chamber. The depth of splitting failure zone between the transformer chamber and tailrace surge chamber is relatively large due to the influence of the fault. The maximum depth of the splitting zone on the downstream sidewall of the main power house is approximately $14.8 \mathrm{~m}$, while the average of that is $6.8 \mathrm{~m}$ after the eighth excavation is completed. The calculated results are almost consistent with the monitoring results shown in Table 1.

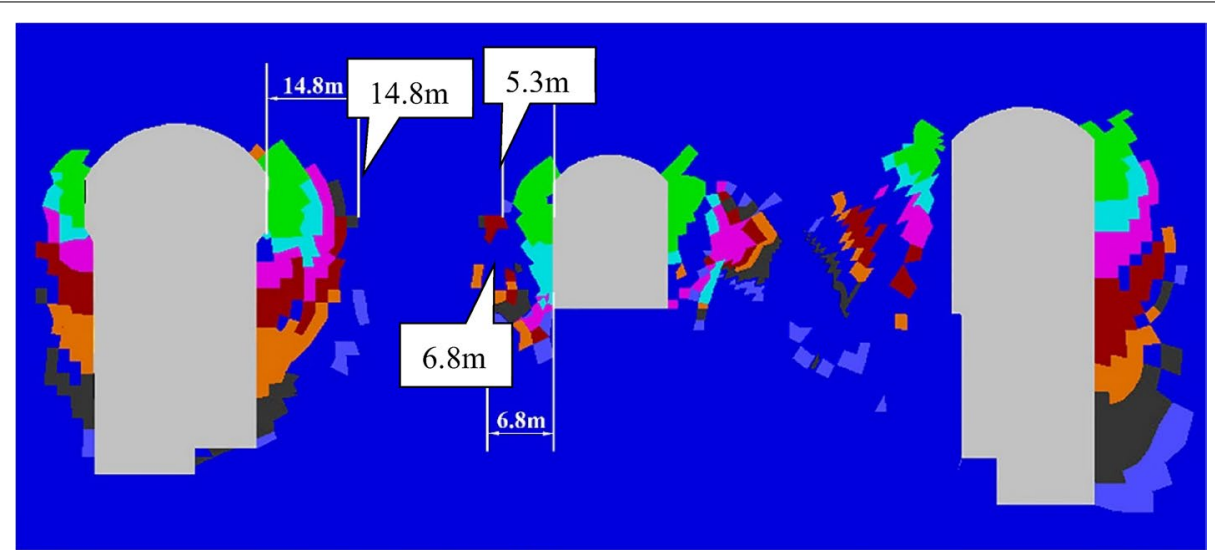

Fig. 7 The splitting area of the generator unit \#4 after eight-step excavation 


\section{Deformation analysis of surrounding rock mass}

For validating the calculation results by FLAC3D, the displacements of some key points in the model, shown in Figs. 3 and 4, have been compared with the displacements obtained by field monitoring at the same positions as in the model, shown in Figs. 8, 9 and 10 .

Since the large size of the main power house, significant disturbing effect on the surrounding rock is caused by excavations of the main power house. Therefore, the displacement of the key points near the downstream surface of the main power house is

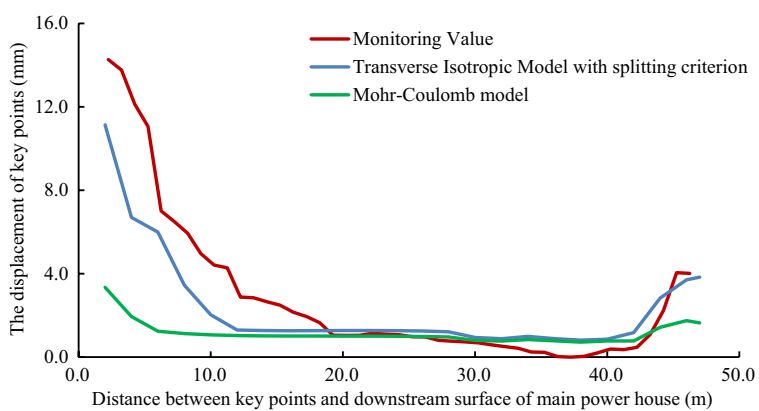

Fig. 8 The displacement curves of the key points of main power house after six-step excavation

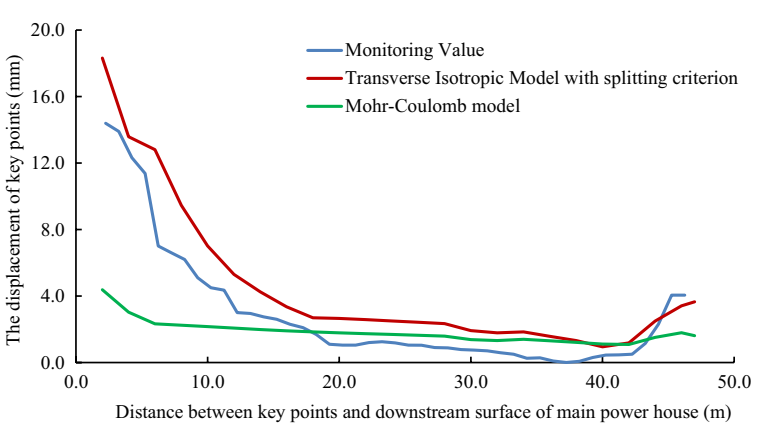

Fig. 9 The displacement curves of the key points of main power house after seven-step excavation

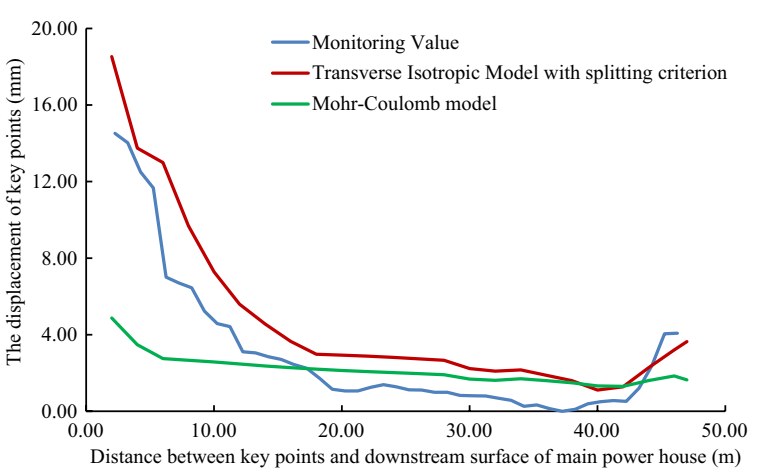

Fig. 10 The displacement of the key points of main power house after eight step excavation 
much larger than that near the upstream surface of the transformer chamber. According to the field monitoring, the maximum displacement of surrounding rock, $18.53 \mathrm{~mm}$, as measured near the surface of the downstream sidewall of the main power house. The displacement of surrounding rock masses decreases with the distance from the surface of the downstream sidewall of the main power house to the key points. The displacement curve has a turning point when the distance between the monitoring points and the main workshop is approximately $15 \mathrm{~m}$. After that, the descending of displacement is becoming insignificant, whereas the displacement is approaching a constant. The displacement of surrounding rock masses begins to be gradually increased when the monitoring points from the surface of the downstream sidewall of the main power house is approximately $41 \mathrm{~m}$ that is $5 \mathrm{~m}$ from the surface of the upstream sidewall of the transformer chamber. The displacement curve reaches a peak when the monitoring point from the surface of upstream sidewall of the transformer chamber is approximately $2 \mathrm{~m}$ away. After the completion of excavation for the eighth step of main power house, the maximum displacement measured at this position is $4.08 \mathrm{~mm}$.

According the comparison of the numerical results, the displacement curves of the key points are relatively flat when only the Mohr-Coulomb model is employed in numerical simulation, and the calculated results of the key points that near the downstream sidewall of the main power house is far less than the monitoring values, approximately $30 \%$ of the later ones, indicating that cavern deformation caused by the splitting failure exists in the rock masses of the downstream sidewall of the main power house, which can be concluded the isotopic Mohr-Coulomb model is inappropriate for numerical modelling in splitting failures of rock mass. On the other hand, when the model of the splitting failure area adopts the transverse isotropic constitutive model, the obtained numerical results are close to the monitoring ones, and the actual displacement can be reflected.

Similar with the monitoring result, it can be seen from the displacement curve, calculated using the transverse isotropic constitutive model, that there are two turnings points in this curve, which appear at the points, 15 and $41 \mathrm{~m}$ from the surface of downstream sidewall of the main power house, respectively. The depth of the splitting zone in the rock mass on upstream side wall of the transformer chamber is approximately $5 \mathrm{~m}$. By comparison the displacement curve that is obtained using transverse isotropic constitutive model is very similar to the monitoring curve.

\section{Analysis of model calculation}

In order to make better understandings of the deformation and stress characteristics of each of the units, the representative key points which are on the vault, rock-bolt crane girder and the surface on the upstream sidewall of main power house and transformer chamber were selected, as well as on the downstream sidewall, as shown in Fig. 11. The extracted displacement data of each key point after calculation in FLAC3D, is shown in Figs. 12, 13, 14, 15 and 16.

After the excavations, the direction of the main deformation of the key points is inside the surrounding rock to the excavating surface, and the deformation of the key point on the vault is mainly vertical, and is horizontal when the key point was on the sidewall. The displacement of the key point of the downstream side wall of the main powerhouse is larger than that of the upstream side wall at the same altitude in unit \#4. The maximum 


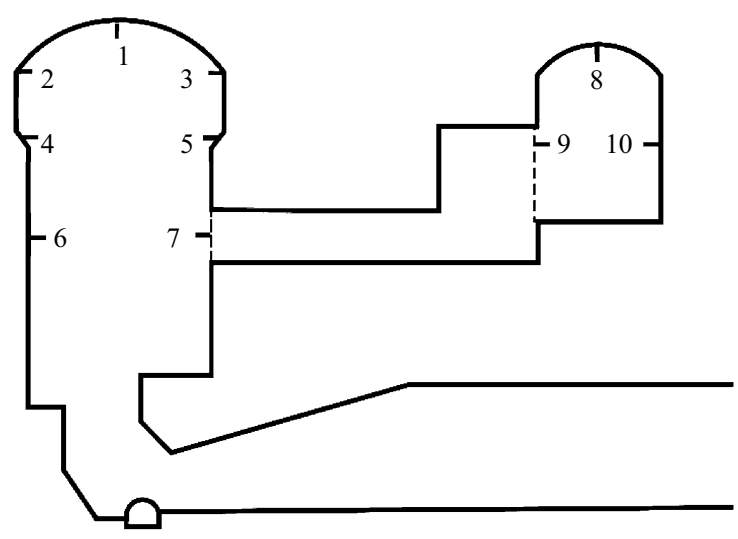

Fig. 11 Distribution of key points of the calculating model in the numerical simulation

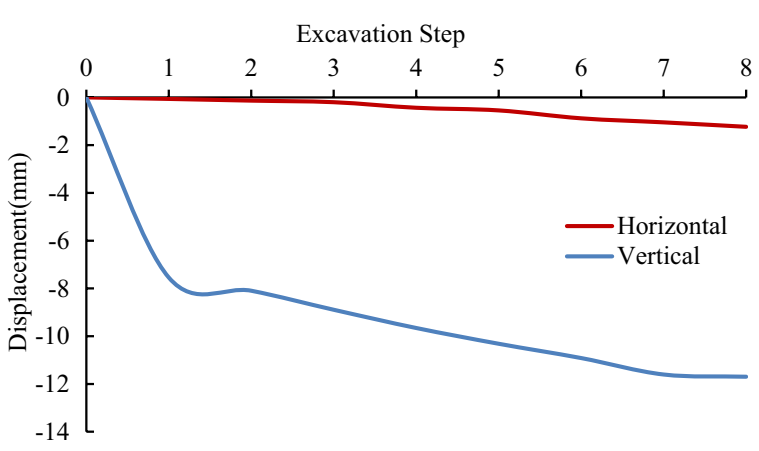

Fig. 12 The displacement curves of the key points \#1 of the main power house

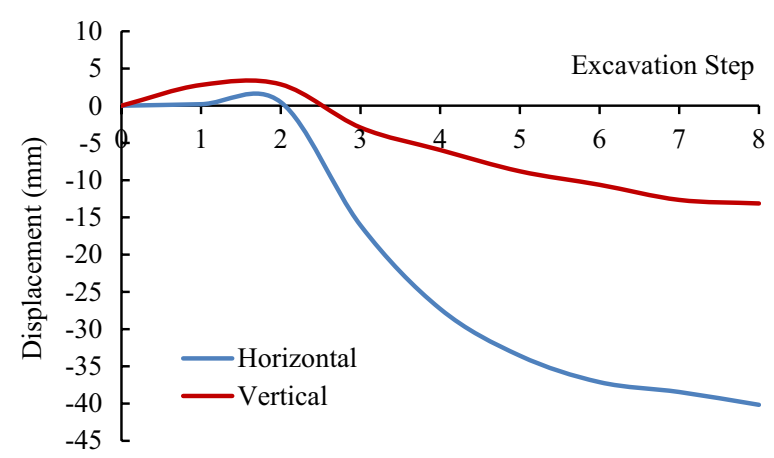

Fig. 13 The displacement curves of the key points \#5 of the main power house

displacement of the key points of the downstream side wall of the main plant of the unit \#4 is the key point \#5 whose horizontal displacement is $35.97 \mathrm{~mm}$ after eight-step excavation. The vertical displacement of the vault of the main power house after one-step excavation is $7.54 \mathrm{~mm}$, and that reaches $11.70 \mathrm{~mm}$ after eight-step excavation. The variation of displacement of the key points of transformer chamber is similar to the main power house. The vertical displacement of the vault of the main power house is $6.62 \mathrm{~mm}$ 


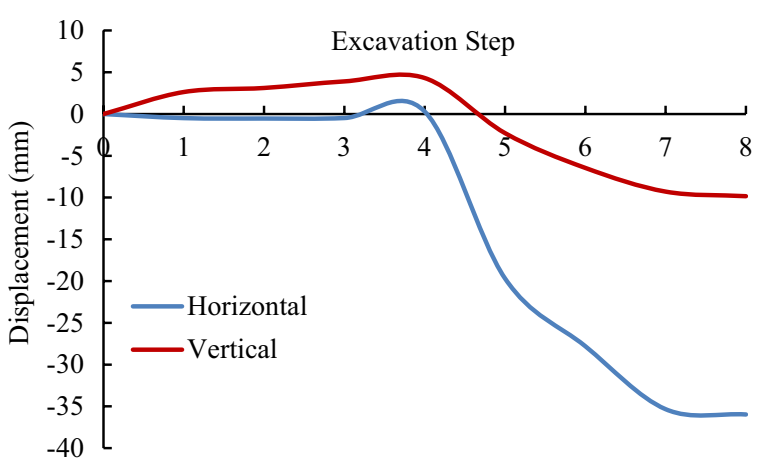

Fig. 14 The displacement curves of the key points \#7 of the main power house

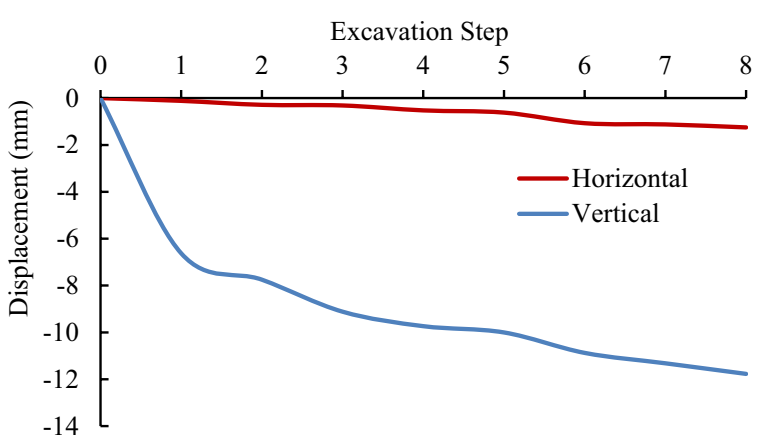

Fig. 15 The displacement curves of the key points \#8 of the transformer chamber

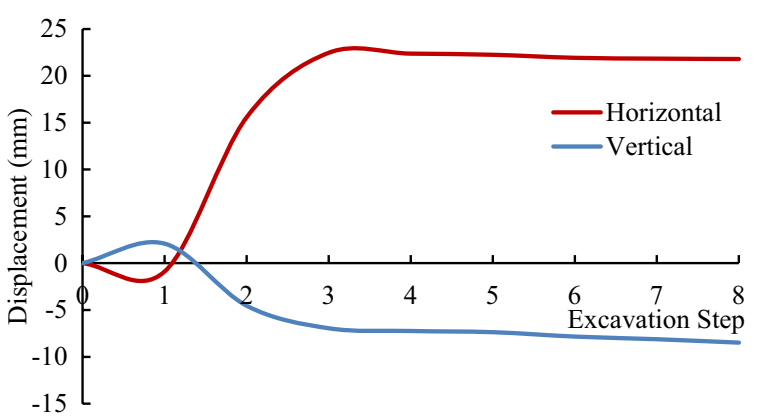

Fig. 16 The displacement curves of the key points \#9 of the transformer chamber

after the one-step of excavation and increases to $11.77 \mathrm{~mm}$. The horizontal displacement of the upstream sidewall of transformer chamber is $21.80 \mathrm{~mm}$ after the eight-step excavation, which is larger than that of the downstream sidewall.

\section{Summary and conclusion}

1. Field monitoring has been taken in generator unit \#4 of Dagangshan Hydropower Station. Two monitoring holes has been constructed, and the splitting phenomenon of the rock masses between the main power house and transformer chamber has been monitored through the borehole TV, sliding extensometer and WDA-1 defor- 
mation resistivity instrument. According to the displacement monitoring results, the displacement of the rock masses decreases with the distance between the main power house and transformer chamber increasing at the beginning, and when the distance is over $41 \mathrm{~m}$, the displacement is increasing again. The maximum displace-

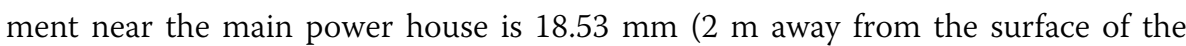
downstream sidewall of the main power house), and that near the transformer chamber is $4.08 \mathrm{~mm}$ ( $5 \mathrm{~m}$ away from the surface of the upstream sidewall of the transformer chamber). The monitoring result also shows that the depth of the splitting zone of downstream sidewall of main power house is larger than that of upstream sidewall. And the depth of the downstream sidewall of the main power house is approximately 13-15 $\mathrm{m}$, and that of the upstream sidewall of the transformer chamber is approximately $5 \mathrm{~m}$.

2. A numerical model of generator unit \#4 with main power house, transformer chamber and tailrace surge chamber has been established and a transverse isotropic constitutive model and a splitting failure criterion are simultaneously employed to calculate the splitting zone of the surrounding rock masses. The maximum depth of the splitting area of the downstream sidewall of the main power house by calculation is approximately $14.8 \mathrm{~m}$ and the average of that of the upstream sidewall of the transformer chamber is approximately $6.8 \mathrm{~m}$, which are similar with the monitoring values. By comparing the calculated and actually monitored displacement curve, it can be concluded that the displacement curve calculated with transverse isotropic constitutive model is more consistent with the actual field monitoring curve. In this way, the employment of the transverse isotropic constitutive model could numerically simulate splitting zones in brittle surrounding rock mass under high in situ stress.

3. The calculated displacement by the new model which considering the opening deformation is three times larger than that obtained by traditional elasto-plastic constitutive model. The results calculated by the new model with the transverse isotropic model are more closed to the monitoring values.

4. By analyzing the displacement curve, it can be seen that the curve has two inflections when the distances between the key points and the surface of the downstream sidewall of the main power house are 15 and $41 \mathrm{~m}$, respectively, which means the depth of the splitting area of the downstream sidewall of the main power house is approximately $15 \mathrm{~m}$ and that of the upstream sidewall of the transformer chamber is approximately $5 \mathrm{~m}$. The results show that the calculated curve is consistent with the field monitoring result.

Authors' contributions

This work was carried out in collaboration between all authors. ZW and YL completed the field monitoring work and wrote the whole manuscript in this research. YX and SY performed the analysis of the experimental results. WZ provided the theoretical guidance of the constitutive model. All authors read and approved the final manuscript.

\section{Author details}

${ }^{1}$ Geotechnical and Structural Engineering Research Center, Shandong University, Jinan 250061, Shandong Province, People's Republic of China. ${ }^{2}$ School of Civil Engineering, Shandong University, Jinan 250061, Shandong Province, People's Republic of China.

\section{Acknowledgements}

The work is supported by National Science and Technology Support Program of China (Grant No. 2015BAB07B05), and the National Natural Science Foundation of China (Grant Nos. 51379112, 51422904, 51579140 and 51609130), and the Fundamental Research Funds of Shandong University (Grant Nos. 2015JX003 and 2016JC007), and China Postdoctoral Science Foundation funded project (No. 2016M592213). We would also like to express our sincere gratitude to the editor and the two anonymous reviewers for their valuable contributions to this paper. 
Competing interests

The authors declare that they have no competing interests.

Received: 15 June 2016 Accepted: 5 September 2016

Published online: 13 September 2016

\section{References}

Aboye SA, Nadarajah R (2012) A numerical approach of failure mechanism of transversely isotropic rocks. US Rock Mech 4:2794-2798

David O (2012) Application of a transversely isotropic brittle rock mass model in roof support design. Int J Min Sci Technol 22:639-643

Dias-da-Costa D, Veludo J, Alfaiate J, Júlio E (2011) An element enriched formulation for simulation of splitting failure. Eng Fract Mech 78:301-316

Haeri H, Marji MF, Shahriar K et al (2014) On the HDD analysis of micro crack initiation, propagation, and coalescence in brittle materials. Arab J Geosci 8:1-12

Haeri H, Khaloo A, Marji MF (2015) Experimental and numerical analysis of Brazilian discs with multiple parallel cracks. Arab J Geosci 8:5897-5908

Hibino S, Motojma M (1995) Characteristic behavior of rock mass during excavation of large caverns. In: Proceedings of 8th international congress on rock mechanics, pp 553-586

Janna C, Castelletto N, Ferronato M, Gambolati G, Teatini P (2012) A geomechanical transversely isotropic model of the Po River basin using PSInSAR derived horizontal displacement. Int J Rock Mech Min Sci 51:105-118

Jia P, Tang CA, Zhang GL (2008) Failure mechanism study on vertically stratified rock mass around deep tunnel. J Northeast Univ 29:893-896

Jiang Q (2007) Study on model and stability of surrounding rock of large underground caverns under high geo-stress condition. Dissertation, the Chinese Academy of Sciences (in Chinese with English abstract)

Li XJ (2007) Experimental and theoretical studies of formation mechanism of splitting failure of the deep cavern. Dissertation, Shandong University (in Chinese with English abstract)

LiY (2009) Study on the stability induced by stepped excavations and rheological effect of underground cavern groups in high in situ stress areas. Dissertation, Shandong University (in Chinese with English abstract)

Li XJ, Zhu WS, Li SC, Yang WM (2011) A new displacement prediction method of brittle jointed rock mass considering excavation unloading splitting effect. Chin J Rock Mech Eng 30:1445-1453 (in Chinese with English abstract)

Li Y, Zhu WS, Fu JW, Guo YH, Qi YP (2014) A damage rheology model applied to analysis of splitting failure in underground caverns of Jinping I hydropower station. Int J Rock Mech Min 71:224-234

Liu N (2009) Study on mechanical mechanism and energy analysis model of splitting failure in high geostress. Dissertation, Shandong University (in Chinese with English abstract)

Ngueyep Mambou LL, Ndop J, Ndjaka J-MB (2015) Numerical investigations of stresses and strains redistribution around the tunnel: influence of transverse isotropic behavior of granitic rock, in situ stress and shape of tunnel. J Min Sci 51:497-505

Nie TY, Pu H, Liu GH, Xiao C, Ni HY (2015) Research on splitting failure model of fractured rock mass under the coupling effect of seepage-stress. J Min Saf Eng 32:1026-1030, 1036 (in Chinese with English abstract)

Wei JB, Deng JH, Wang DK, Cai DW, Hu JZ (2010) Characterization of deformation and fracture for rock mass in underground powerhouse of Jinping I hydropower station. Chin J Rock Mech Eng 29:1198-1205 (in Chinese with English abstract)

Xiang TB, Feng XT, Jiang Q, Chen JL, Wan XB (2011) Failure mode dynamic recognition and control for surrounding rock of large-scale cavern group. Chin J Rock Mech Eng 30:871-883 (in Chinese with English abstract)

Yerramalli CS, Waas AM (2001) Compressive splitting failure in fiber reinforced unidirectional composites using modified shear lag theory. Collect Tech Pap AIAA ASME ASCE AHS Struct Struct Dyn Mater 4:2930-2937

Zhang JG, Zhang QY, Yang WD, Zhang X (2009) Regression analysis of initial geostress field in dam zone of Dagangshan hydropower station. Rock Soil Mech 30:3071-3078 (in Chinese with English abstract)

Zhang HY, Wei Q, Sheng Q, Leng XL, Jing F (2011) Three dimensional back analysis of geostress field in underground powerhouse zone of Dagangshan hydropower station. Rock Soil Mech 32:1523-1530 (in Chinese with English abstract)

Zhang Y, Xiao PX, Ding XL, Ou WB, Lu B, Liao CG, Dong HZ (2012) Study of deformation and failure characteristics for surrounding rocks of underground powerhouse caverns under high geostress condition and countermeasures. Chin J Rock Mech Eng 31:228-244 (in Chinese with English abstract)

Zhu WS, Li Y, Li SC, Wang SG, Zhang QB (2011) Quasi-three-dimensional physical model tests on a cavern complex under high in situ stresses. Int J Rock Mech Min 48:199-209

Zhu WS, Qi YP, Guo YH, Yang WM (2012) 3D damage rheology analysis of deformation and fracture of surrounding rocks in Jinping I hydropower station underground powerhouse. Chin J Rock Mech Eng 31:865-872 (in Chinese with English abstract) 